\title{
Occult celiac disease in an octogenarian presenting with a small intestinal adenocarcinoma
}

\author{
HUGH JAMES FREEMAN MD
}

HJ FREEMAN. Occult celiac disease in an octogenarian presenting with a small intestinal adenocarcinoma. Can J Gastroenterol 1994;8(6):354-357. An 85-year-old male initially presented with an obstructed upper gastrointestinal tract associated with a duodenal adenocarcinoma. Subsequent histological studies revealed occult celiac disease, an associated condition that otherwise would not have been recognized in this elderly patient. The celiac disease responded to a gluten-free diet, even in the presence of an intestinal adenocarcinoma. This report suggests that celiac disease and small bowel carcinoma may coexist more frequently than is appreciated.

Key Words: Celiac disease, Duodenal adenocarcinoma, Gluten-free diet, Malabsorption syndromes, Occult celiac disease, Small bowel cancer

\section{Maladie coeliaque occulte chez un octogénaire qui se présente avec un adénocarcinome de l'intestin grêle}

RÉSUMÉ : Un homme de 85 ans se présente initialement avec une obstruction des voies gastro-intestinales supérieures associée à un adénocarcinome duodénal. Des épreuves histologiques subséquentes ont révélé une maladie coeliaque occulte, maladie associée qui n'aurait pu être autrement identifiée chez ce patient âgé. La maladie coeliaque a répondu à une diète sans gluten, même en présence d'un adénocarcinome intestinal. Ce rapport suggère que la maladie coeliaque et le carcinome de l'intestin grêle peuvent coexister plus fréquemment que l'on ne penserait.

$\mathrm{P}$ ATIENTS WITH CELIAC DISEASE have an increased risk of developing malignant complications, especially abdominal lymphoma (1-3). In addition, some epithelial malignancies appear to occur more commonly in patients with celiac disease compared with the general population; these include carcinomas of the gastrointestinal tract, including the small intestine (4). Although earlier studies have indicated that malignancy may complicate long-standing celiac disease, subsequent investigations revealed that

University Hospital (UBC Site), Vancouver, British Columbia

Correspondence and reprints: Dr. Hugh J Freeman, Head, Gastroenterology, ACU F-137 University Hospital (UBC Site), 2211 Wesbrook Mall, Vancouver, British Columbia V6T 1W5. Telephone (604) 822-7216

Received for publication December 13, 1993. Accepted April 12, 1994

lymphomas, particularly of the small intestine, could be the presenting manifestation of occult or subclinical celiac disease (3) as well as latent celiac disease (5).

It is increasingly recognized that carcinomas of the proximal intestine, specifically the duodenum and jejunum, may also occasionally complicate the clinical course of established celiac disease (6-34). However, precise data on the true relationship between these two conditions are not available, in large part because recognition of celiac disease, particularly if symptoms are minimal, is difficult. Diagnosis of celiac disease rests on at least two criteria. One is the finding of a characteristic 'flat' mucosa in the proximal small intestine. The second is the demonstration of a response to a gluten-free diet. In a clinical diagnostic setting, a successful therapeutic response is often based on the disappearance of symptoms and normalization of laboratory abnormalities. However, if the initial clinical presentation is occult with few symptoms and little or no steatorrhea, documentation of a morphological response is important.

In the present report, the opposite end of this celiac disease-carcinoma relationship is explored. An elderly patient with an adenocarcinoma of the duodenum was seen; subsequently, occult celiac disease was recognized. Although more systematic studies are needed, this report further emphasizes 
the occult nature of celiac disease and suggests that the association of celiac disease and small intestinal cancer is more frequent than is appreciated.

\section{CASE PRESENTATION}

An 85-year-old male was first hospitalized in October 1989 because of sudden onset of severe postprandial abdominal pain and vomiting of fluids and solids. Prior to this acute presentation he had intermittent postprandial abdominal discomfort and bloating for approximately eight months with an estimated weight loss of $10 \mathrm{~kg}$. Medical history was unremarkable and, specifically, there was no prior diarrhea, fever or known anemia. Examination revealed abdominal distension with a succussion splash. Abdominal radiographs showed gastric distension and a gastric outlet obstruction was suspected. Laboratory investigations showed a mild normochromic, normocytic anemia with a hemoglobin of 129 $\mathrm{g} / \mathrm{L}$. Biochemical tests were normal including serum electrolytes, calcium, liver chemistry tests, amylase, proteins and albumin $(37 \mathrm{~g} / \mathrm{L})$. An initial endoscopic evaluation revealed fluid and food debris in the stomach; the procedure was terminated to avoid aspiration.

After decompression with a nasogastric tube, a gastrograffin contrast study revealed gastric dilation and impaired gastric emptying with apparent obstruction of the duodenal loop. Contrast material could not be identified in the distal duodenum and an irregular mucosal contour was suspected (Figure 1). Endoscopic re-evaluation showed some retained food debris in the gastric antrum and proximal duodenum; in addition, a food bolus appeared to be impacted in the distal descending duodenum. This was removed with a polyp snare wire. The mucosa in the distal duodenum, however, was abnormally nodular and slightly friable; scalloping of duodenal folds was not seen. Proximal duodenal bulbar mucosal biopsies showed moderately severe villous flattening with hyperplastic crypts while biopsies from the proximal descending duodenum were normal. Biopsies from the abnormal-appearing distal duodenal mucosa revealed a well-differentiated duodenal adenocarcinoma (Figure 2). Gastric biopsies showed epithelial lymphocytosis consistent with lymphocytic gastritis (35).

A contrast-enhanced abdominal computed tomography scan confirmed a soft tissue mass in the third portion of the duodenum while the common bile duct and pancreas were normal. Laparotomy was done; a circumferential fibrosing duodenal tumour mass was present in the third portion of the duodenum. Because of the age of the patient and the location of the tumour near the superior mesenteric artery, the surgeon elected not to attempt tumour resection; a gastrojejunostomy to bypass the tumour was performed. Further needle biopsies of the duodenal mass done during the laparotomy also confirmed adenocarcinoma. He recovered following surgery and was discharged

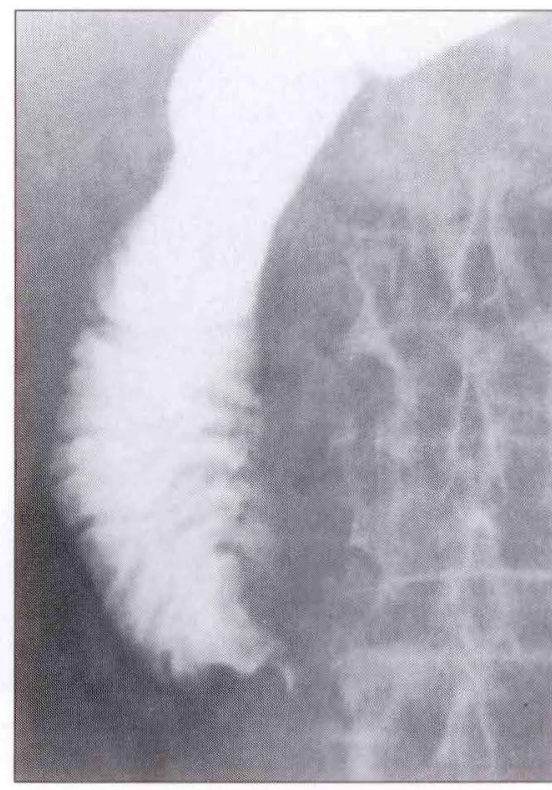

Figure 1) Contrast study showing a narrowed distal duodenum; contrast was not observed to pass an obstruction

home on a normal diet. No other treatment was provided.

In April 1993 the patient was reevaluated for suspected celiac disease. This possibility of celiac disease diagnosis was raised following a review of his biopsies from 1989 for a clinical conference done for teaching purposes; the patient had no gastrointestinal symptoms. Endoscopic examination was repeated and showed the distal duodenal tumour mass; biopsies of distal duodenum immediately proximal to the tumour as well as to the jejunum were normal, but biopsies of the duodenal bulb and proximal descending duode-
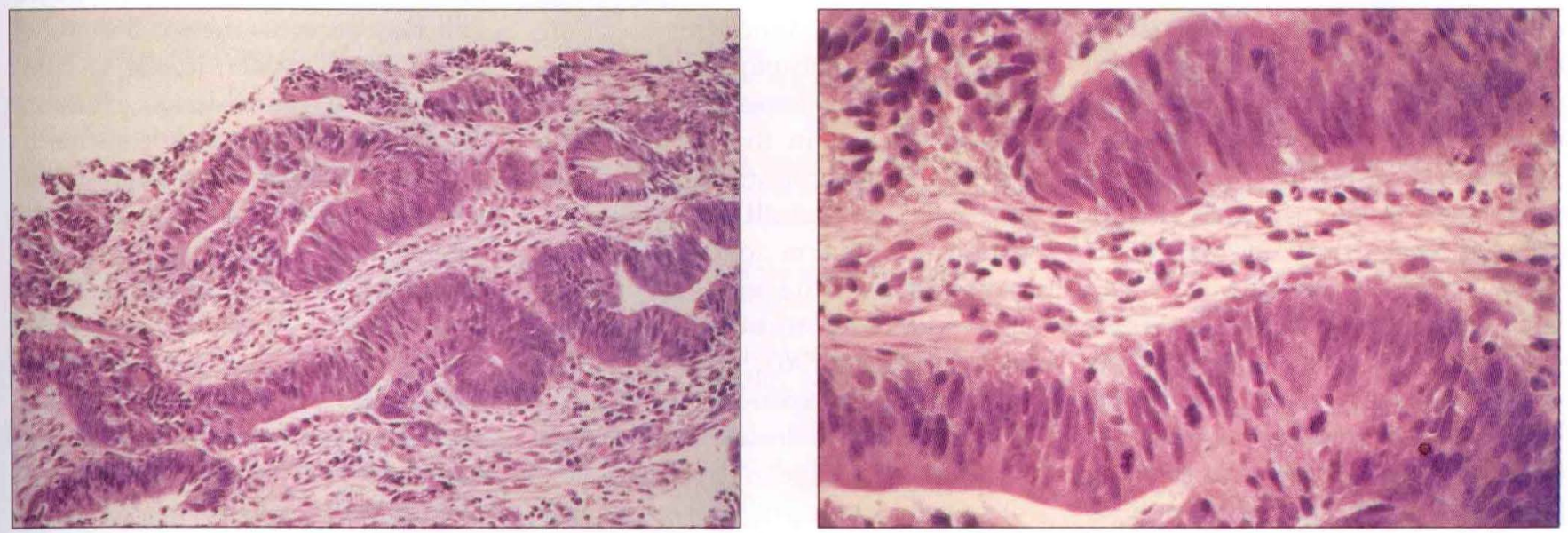

Figure 2) Endoscopic biopsy showing a duodenal adenocarcinoma. Left Low power; Right High power 


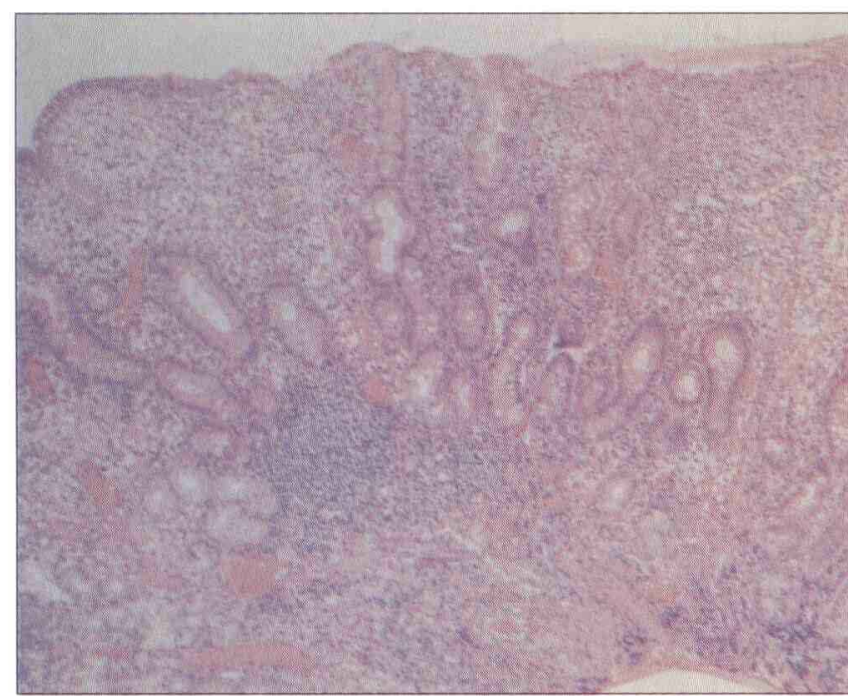

Figure 3) Small intestinal endoscopic biopsy from the proximal duodenum showing flattened villi with crypt hyperplasia; increased numbers of lymphoid cells are present in the lamina propria and surface epithelium. The changes represent a severely abnormal 'flat' small intestinal mucosal lesion typical of untreated celiac disease

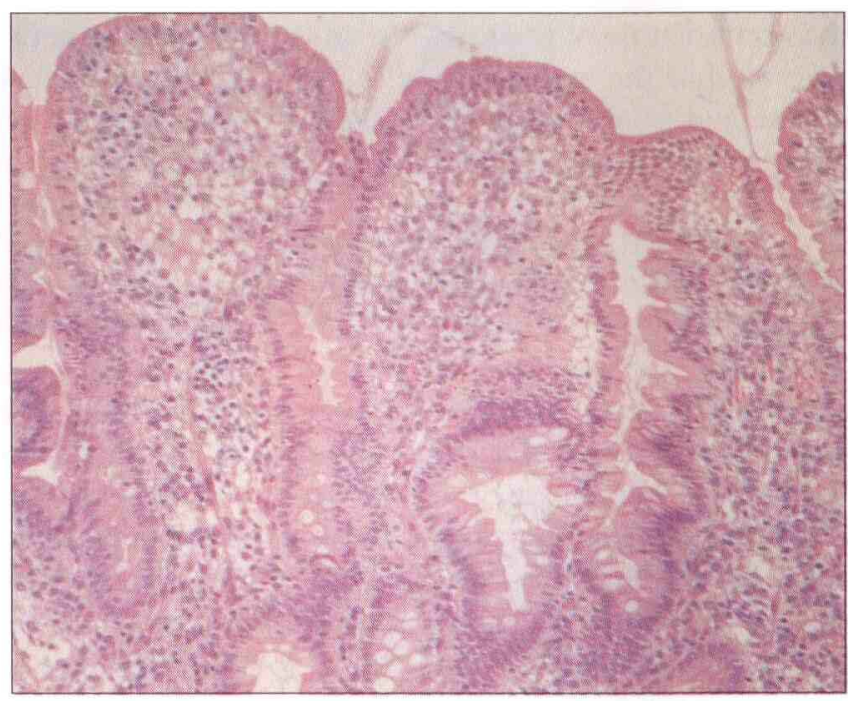

Figure 4) Small intestinal biopsy from the proximal duodenum showing improved mucosal architecture with the reappearance of villi after six weeks on a gluten-free diet in hospital; although mild to moderate changes persist, this biopsy histologically confirms the ghten-sensitive nature of the mucosal lesion in occult celiac disease num showed changes identical to those observed in 1989 with moderately severe villous flattening and crypt hyperplasia (Figure 3). The patient was hospitalized and administered a strict gluten-free diet. Additional endoscopic biopsies from the proximal duodenum after six weeks on this diet showed normalized architecture with re-appearance of villi (Figure 4).

\section{DISCUSSION}

The first well documented patient with coexistent celiac disease and an adenocarcinoma of the small intestine was recorded in the case records of the Massachusetts General Hospital in 1958 (25). Later, several patients were described, usually with a carcinoma localized in the duodenum or jejunum and, occasionally, ileum (23). Most often, a single site of carcinoma was reported but, like small intestinal lymphomas in celiac disease (5), multifocal carcinoma was also described (14). In celiac patients with cancer, diagnosis of the malignancy was usually established late in the clinical course, most often was reported in males and usually, but not always, was diagnosed after the celiac disease was detected. Interestingly, diagnosis of celiac disease in some reported patients was sometimes only established late in this setting and often only minimal clinical symptoms of celiac disease were reported.

The elderly male patient described here had no clinical symptoms or biochemical changes that would have suggested malabsorption or a diagnosis of celiac disease prior to his urgent clinical presentation with an obstructed upper gastrointestinal tract. In retrospect, the limited extent of the morphological abnormalities documented in his proximal small intestine may have contributed to the absence of symptoms. In occult celiac disease, there is more than enough mucosa in the distal small intestine to absorb most nutrients (3).

Although the patient was administered a gluten-free diet in hospital in the setting of a clinical investigation unit to confirm histologically the diagnosis of celiac disease, the role of a gluten-free diet in the prevention of malignant complications associated with celiac disease still requires investigation. Long term follow-up studies have addressed this issue, particularly in a series of reports from Birmingham in England. In 1967, Harris et al (1) reviewed their experience in $202 \mathrm{pa}$ tients with celiac disease and observed a statistical increase in lymphoma. In a subsequent report in 1976, Holmes et al (27) reported on the same patient group and suggested that a protective role for a gluten-free diet could not be defined, possibly due to the limited strictness of the diet and its duration for an average of only 7.5 years; longer term studies were planned. In 1989, the same group re-evaluated their patients after a further 11 years of surveillance (36); in that study, no increased risk of malignancy was identified in those consuming a gluten-free diet for at least five years while an increased risk was present in those on a reduced-gluten or an entirely normal diet. The possible role of a gluten-free diet in the prevention of small bowel cancer still needs evaluation.

Some reports $(37,38)$ suggested that morphological changes of flattened villi may occur in the small bowel of patients with cancer, ie, the so-called 'cancer enteropathy' lesion. However, careful histological studies unequivocally demonstrated that flattened small intestinal biopsies are not caused by malignancies, including adenocarcinomas of intestinal or nonintestinal sites $(39,40)$. Moreover, in patients with lymphoma, flattened small intestinal biopsies were previously shown to recover morphologically on a glutenfree diet (3). The present report provides further evidence related to this issue: first, the small bowel carcinoma 
in our patient developed in an area with normal small intestinal villous architecture proximal and distal to the cancer; and second, the flattened mucosa in the proximal intestine responded morphologically to a strict gluten-free diet. Moreover, as the cancer was only bypassed, and not resected, the morphological studies here provide additional evidence that the flattened small intestine in celiac disease responds to gluten restriction, even if coexistent small bowel carcinoma is present.

Additional studies are needed to explore further celiac disease factors that predispose to malignant change. A number of mechanisms may be in-

\section{REFERENCES}

1. Harris OD, Cooke WT, Thompson H, Waterhouse JAH. Malignancy in adult celiac disease and idiopathic steatorrhea. Am J Med 1967;42:889-912.

2. Asquith P. Adult coeliac disease and malignancy. J Ir Med Assoc 1974;67:417-20

3. Freeman HJ, Weinstein WM, Shnitka TK, Piercey JRA, Wensel RH. Primary abdominal lymphoma. Presenting manifestation of celiac sprue or complicating dermatitis herpetiformis. Am J Med 1977;63:585-94.

4. Swinson CM, Slavin G, Coles EC, Booth CC. Coeliac disease and malignancy. Lancet 1983;i:111-5.

5. Freeman HJ, Chiu BK. Multifocal small bowel lymphoma and latent celiac sprue. Gastroenterology 1986;90:1992-7.

6. Nielson SN, Wold LE. Adenocarcinoma of the jejunum in association with nontropical sprue. Arch Pathol Lab Med 1986;110:822-4.

7. Brzechwa-Ajdukiewicz A, McCarthy CF, Austad W, Cornes J, Harrison WJ, Read AE. Carcinoma, villous atrophy, and steatorrhoea. Gut 1966;7:572-7.

8. Magnussen PA, Grant JW. Perforation of a jejunal adenocarcinoma complicating coeliac disease. J R Soc Med 1986;79:114-5.

9. Kenwright $\mathrm{S}$. Coeliac disease and small bowel carcinoma. Postgrad Med J 1972;48:673-7.

10. Farrell DJ, Shrimankar J, Griffin SM. Duodenal adenocarcinoma complicating coeliac disease. Histopathology 1991; 19:285-7

11. Pelli MA, Cavalletti ML, Bassotti G, Ribachi F, Morelli A. Adenocarcinoma of the duodenal bulb in a young coeliac woman. Ital J Gastroenterol 1993;25:121-2.

12. Verhulst ML, Dur AH, Driessen WM. Two sisters with coeliac disease and jejunal cancer: just a coincidence? Neth J Med 1993:42:16-20.

13. Straker RJ, Gunasekaran S, Brady PG. Adenocarcinoma of the jejunum in association with celiac sprue. J Clin Gastroenterol 1989;11:320-3.

14. Dannenberg A, Godwin T, Rayburn J, volved (2). The morphological changes seen in untreated celiac disease may be important. Increased mitotic activity in the crypts and lymphoid cells of the small intestinal mucosa with increased cell turnover have been hypothesized to represent a premalignant change (2). Carcinogens might also more readily penetrate the damaged mucosal surface that is deficient in carcinogen-detoxifying enzymes (2). This could result in malignancies, not only in the gastrointestinal tract, but also external to the gastrointestinal tract. An abnormal or altered immune system resulting in impaired immune surveillance may also predispose to the development of malignancy (2), particularly lymphoma.

Goldin H, Leonard M. Multifocal adenocarcinoma of the proximal small intestine in a patient with celiac sprue. J Clin Gastroenterol 1989;11:73-6.

15. Javier J, Lukie B. Duodenal adenocarcinoma complicating celiac sprue. Dig Dis Sci 1980;25:150-3.

16. Levine ML, Dorf BS, Bank S. Adenocarcinoma of the duodenum in a patient with nontropical sprue. Am J Gastroenterol 1986;81:800-2.

17. Fric P, Bednar B, Niederle B, Lepsik J. Jejunal adenocarcinoma in a woman with nontropical sprue. Gastroenterology 1963;44:330-4

18. Holmes GKT, Dunn GI, Cockel R, Brookes VS. Adenocarcinoma of the upper small bowel complicating coeliac disease. Gut 1980;21:1010-6.

19. O'Brien CJ, Saverymuttu S, Hodgson HJF, Evans DJ. Coeliac disease, adenocarcinoma of the jejunum and in situ squamous carcinoma of the oesophagus. J Clin Pathol 1983;36:62-7.

20. Petreshock EP, Pessah M, Menachemi E. Adenocarcinoma of the jejunum associated with nontropical sprue. Dig Dis 1975;20:796-802.

21. Joske RA. Primary carcinoma of jejunum with atrophic jejunitis and intestinal malabsorption. Gastroenterology 1960;38:810-6.

22. Moertel CG, Hargraves MM. Coexistence of adenocarcinoma of the jejunum and nontropical sprue. JAMA $1961 ; 176: 612-4$

23. Girdwood RH, Delamore IW, Williams AW. Jejunal biopsy in malabsorptive disorders of the adult. $\mathrm{Br}$ Med J 1961;1:319-23.

24. Lee FD. Nature of the mucosal changes associated with malignant neoplasms in the small intestine. Gut 1966;7:361-7.

25. Case records of the Massachusetts General Hospital (case 44362). N Engl J Med 1958;259:491-5.

26. Selby WS, Gallagher ND. Malignancy in a 19 year experience of adult celiac disease. Dig Dis Sci 1979;24:684-8.

27. Holmes GKT, Stokes PL, Sorahan TM, Prior P, Waterhouse JAH, Cooke WT.
This malignancy has been commonly observed in patients with a variety of diseases having some form of immunological alteration (ie, Sjogren's syndrome, systemic lupus erythematosis, sarcoidosis, post-transplantation), patients with diseases having well-documented deficiencies in humoral (ie, hypogammaglobulinemia) or cellular immune function (ie, acquired immunodeficiency syndrome) as well as in patients receiving immunosuppressive drugs. A gluten-free diet restores the mucosal architecture and mucosal function towards normal in celiac disease and, as a result, has been hypothesized (2) to reduce its malignant potential.

Coeliac disease, gluten-free diet, and malignancy. Gut 1976;17:612-9.

28. Grun M, Schulz A, Kraus J, Leinweber B. Ileus symptoms due to three distinctively differentiated small intestine carcinomas in nontropical sprue. Dtsch Med Wochenscht 1989;114:709-11.

29. Maurano A, Cirillo LC, Noviello A. Celiac disease as a risk factor for digestive neoplasms. Radiol Med (Torino) 1987;73:174-7.

30. Jacobsen MB, Fausa O, Elgjo K, Schrumpf E. Hepatic lesions in adult coeliac disease. Scand J Gastroenterol 1990;25:656-62.

31. Marsch SC, Heer M, Sulser H, Hany A. Adenocarcinoma of the small intestine in celiac disease. Case report and literature review. Schweiz Med Wochenschr 1990;120:135-41.

32. O'Driscoll BRC, Stevens FM, O'Gorman TA, et al. HLA type of patients with coeliac disease and malignancy in the west of Ireland. Gut 1982;23:662-5.

33. Ashkenazi A, Baratz M. Malignancy complicating celiac disease. In: Branski D, Rozen P, Kagnoff MF, eds. Gluten-Sensitive Enteropathy. Basel: Karger, 1992:184-93.

34. Blackwell JB. Two cases of carcinoma of the small bowel with malabsorption. Gut 1961;2:377.

35. Wolber R, Owen D, Belbuono L, Appelman $\mathrm{H}$, Freeman HJ. Lymphocytic gastritis in patients with celiac sprue or spruelike intestinal disease. Gastroenterology 1990;98:310-5.

36. Holmes GKT, Prior P, Lane MR, Pope D, Allan RN. Malignancy in celiac disease effect of a gluten-free diet. Gut 1989;30:333-8.

37. Brunt PW, Sircus W, Maclean N. Neoplasia and the coeliac syndrome in adults. Lancet 1969;1:180-4.

38. Barry RE, Read AE. Coeliac disease and malignancy. Q J Med 1973;42:665-75.

39. Gilat T, Fischel B, Danon J, Loewenthal M. Morphology of small bowel mucosa in malignancy. Digestion 1973;7:147-55.

40. Cooke WT, Thompson H, Williams JA. Malignancy and adult coeliac disease. Gut 1969;10:108-11. 


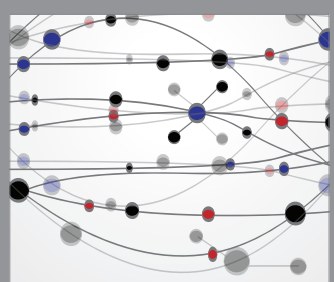

The Scientific World Journal
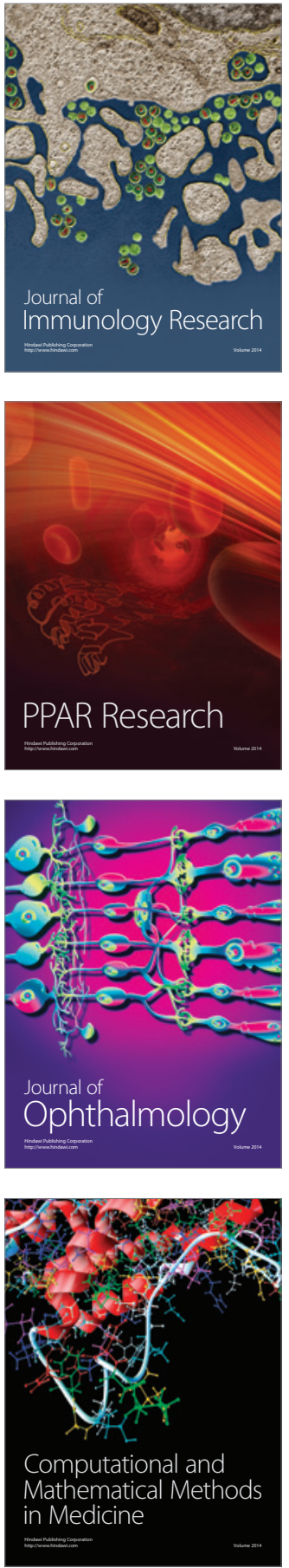

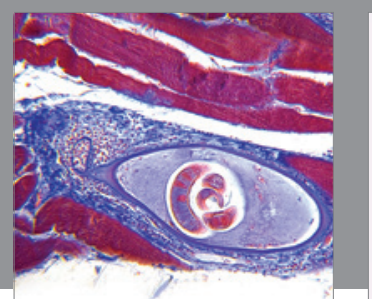

Gastroenterology Research and Practice

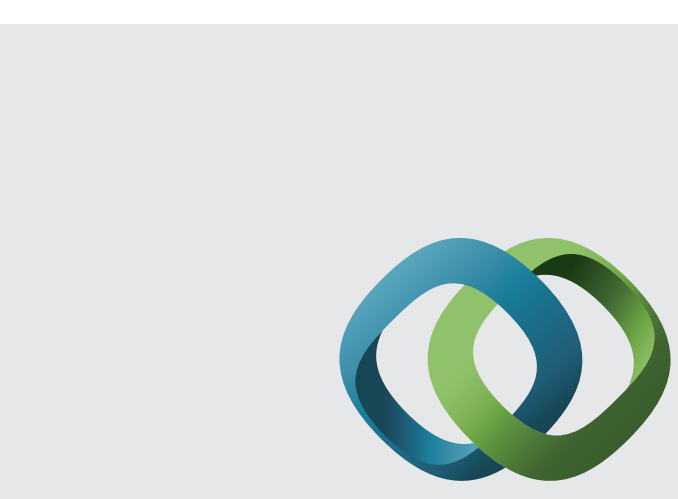

\section{Hindawi}

Submit your manuscripts at

http://www.hindawi.com
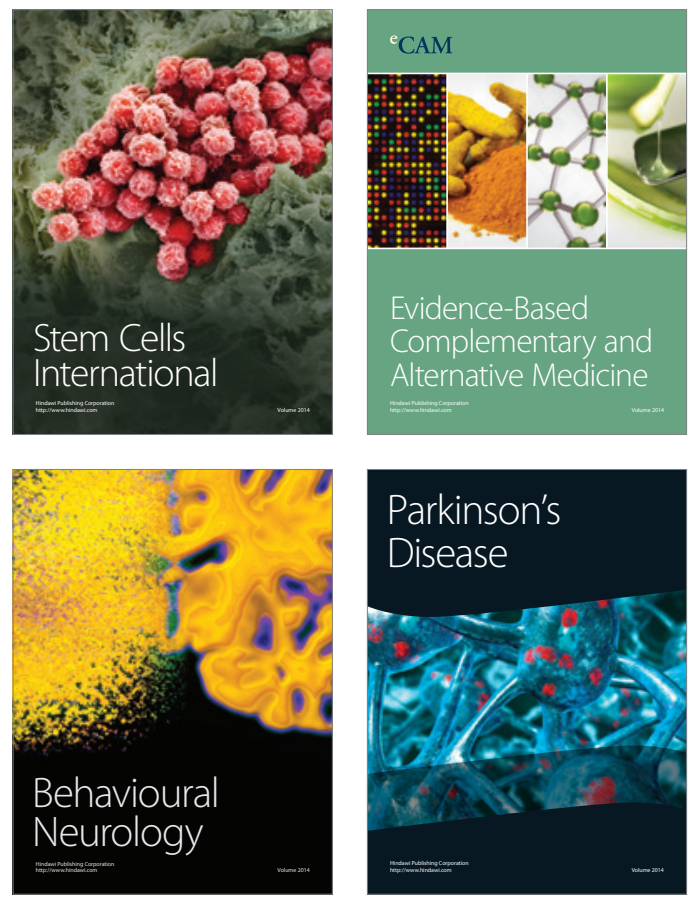
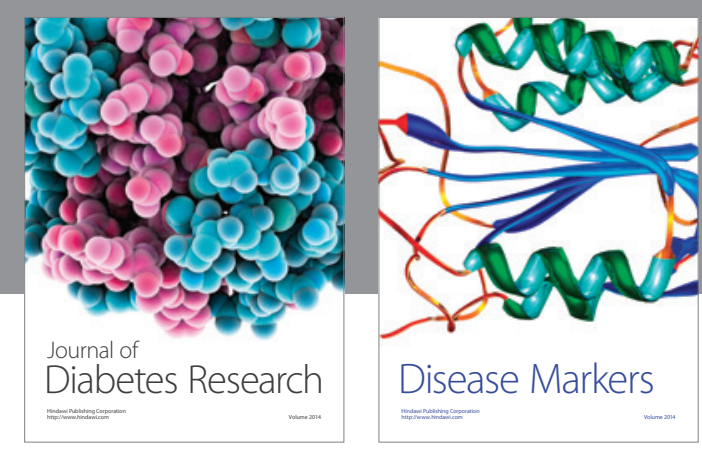

Disease Markers
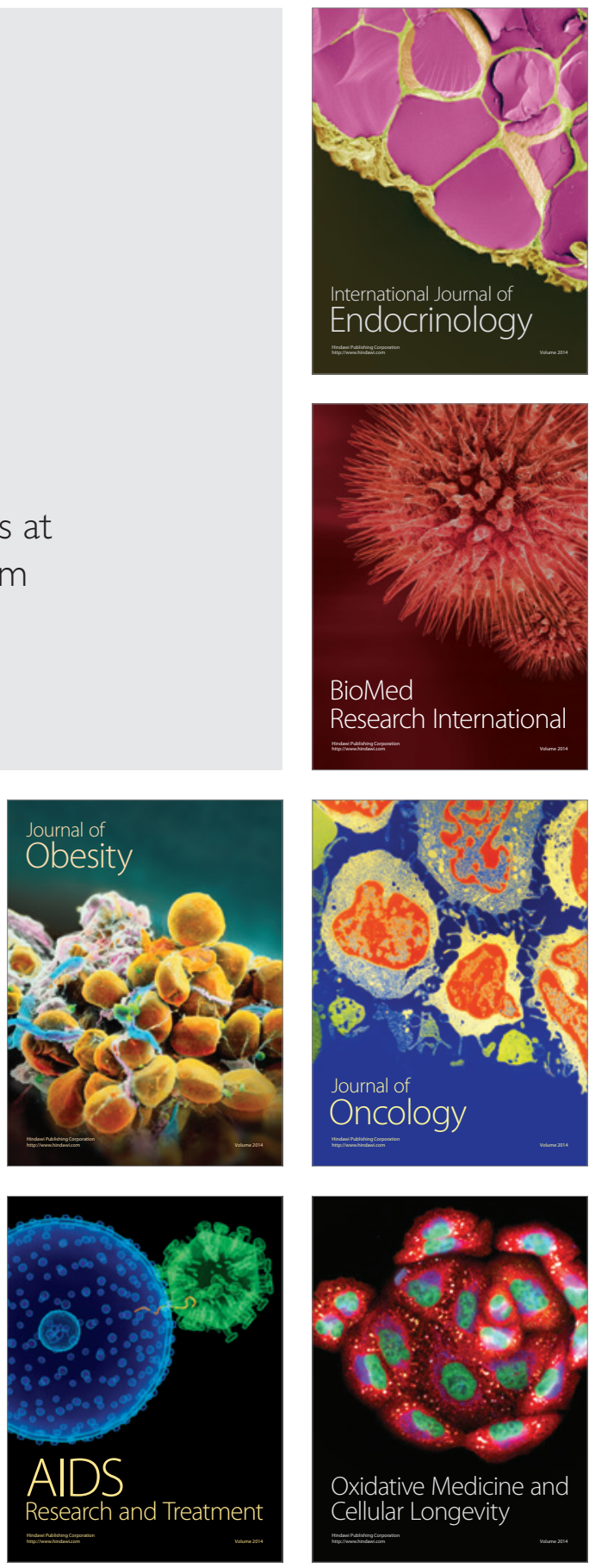